\title{
EFEITO DA ADUBAÇÃO FOLIAR COM MICRONUTRIENTES NA PRODUÇÃO E DIAMETRO DA CEBOLA
}

\author{
SANTOS, Jefferson Oliveira Mendes dos ${ }^{1}$ \\ ZERA, Fabricio Simone ${ }^{2}$ \\ PULICI, Elvis \\ MACHADO, Caroline Maira Miranda ${ }^{1}$
}

\begin{abstract}
RESUMO: O objetivo do trabalho foi avaliar o efeito dos fertilizantes foliares na melhoria da produtividade e da classificação de tamanho de bulbos de cebola. O ensaio foi montado e conduzido em Monte Alto (SP), sendo realizado em seu cultivo comercial. O híbrido de cebola utilizado foi Cristalina, em que foi semeada no dia 12 de maio de 2014, a colheita foi realizada no dia 24 de setembro de 2014. Para o ensaio foi empregado o delineamento em blocos casualizados com 4 tratamentos: Fertilizantes foliares usados foram o Liqui-Plex ${ }^{\circledR}$ Unix $\left(1,0 \mathrm{~L} \mathrm{ha}^{-1}\right)$, Bionex (1,0 L ha), Torped (1,0 L ha) e testemunha sem aplicação, com 5 repetições, constituídas por parcelas de 7,8 $\mathrm{m}^{2}$. Foram realizadas 5 aplicações em intervalos de 14 dias, iniciando a aplicação 34 dias após o plantio. Quantificou-se o número, peso de bulbos e a classificação de tamanho de bulbos de cebola. Para as avaliações finais foram colhidas as plantas de $3,10 \mathrm{~m}^{2}$ da parte central de cada parcela. O tratamento com Liqui-Plex ${ }^{\circledR}$ Unix proporcionou um aumento de produção e na quantidade de bulbos de cebola das classe 3 e 4 .
\end{abstract}

Palavras-chave: Allium cepa. Fertilizante. Bulbo.

SUMMARY:The objective was to evaluate the effect of foliar fertilizer on improving productivity and onion bulb size classification. The test was set up and conducted in Monte Alto (SP), being held in its commercial cultivation. The onion hybrid used was Cristalina, which was planted on May 12, 2014, with seeder 4 double lines, and the harvest was held on September 24, 2014. For the assay was employed a randomized block design treatment with four foliar Fertilizers were used, the Liqui-Plex Unix $\left(1.0 \mathrm{~L} \mathrm{~h}^{-1}\right)$, the organomineral $\left(1.0 \mathrm{~L} \mathrm{~h}^{-1}\right)$, and the organomineral B $\left(1.0 \mathrm{~L} \mathrm{~h}^{-1}\right)$ and untreated application with 5 repetitions, consisting of plots of $7.75 \mathrm{~m}^{2}$. Five applications were performed in 14-day intervals starting with 34 days after planting application. The number bulbs weight and onion bulbs size classification was quantitated. For the final assessments were harvested plants of $3.10 \mathrm{~m}^{2}$ of the central part of each portion.Treatment with Unix Liqui-Plex resulted in an increase of productivity and the amount of class onion bulbs 3 and 4 .

Keywords: Allium cepa. Fertilizer. Bulb.

\section{INTRODUÇÃO}

No Brasil, a cebola (Allium cepa L.) é considerada a terceira hortaliça mais importante, em valor econômico, superada apenas pelo tomate e a batata, com uma área plantada em 2016 de 56.169 ha, correspondendo a uma produção de $1.563 .986 \mathrm{t}$ e produtividade média de $27,8 \mathrm{t} \mathrm{ha}^{-1}$. A região Sul foi responsável por $50 \%$ da produção nacional, seguida pela região Sudeste $(23,9 \%)$, Nordeste $(18,5 \%)$ e Centro-Oeste (7,6\%) (IBGE, 2017).

Um levantamento realizado pelo Ministério de Integração Nacional mostrou que nos supermercados paulistas a cebola responde por $25,2 \%$ do volume das hortaliças comercializadas. De acordo com centro de qualidade em horticultura da Companhia de Entreposto e Armazéns Gerais do estado de São Paulo é possível encontrar quatro cores de casca, dois formatos, três sabores, além de quatro categorias de qualidade e sete classes de tamanho (CEAGESP, 2001). As instituições de pesquisa e

\footnotetext{
${ }^{1}$ Instituto Taquaritinguense de Ensino Superior "Dr. Aristides de Carvalho Schlobach" - ITES

${ }^{2}$ UNESP Jaboticabal
} 
empresas de sementes investem na oferta de diversidade, atendendo às exigências do mercado e as normas de classificação permitem a caracterização da diversidade.

O mercado brasileiro de cebola é formado hoje por dois cenários. O primeiro, parte do ponto de vista do produtor, que está cada vez mais preocupado em adquirir sementes que garantam maior produtividade e apresentem maior grau de resistência às doenças do campo. Do outro lado, o consumidor, atento ao padrão de qualidade do produto, buscando novas variedades, o que compreende a disposição de produtos classificados e padronizados e seu maior tempo de vida de prateleira (shelf-life). Assim é de suma importância o incremento na produtividade da cebola, como a melhoria na sanidade e na qualidade dos bulbos, sendo estes fatores correlacionados com a nutrição das plantas.

A maioria dos cebolicultores do estado de São Paulo, em especial da microrregião de Monte Alto, estão utilizando demasiadamente a adubação de formulação N-P-K na cultura, além do uso indiscriminado do uso de corretivos de acidez, pois existe grande pressão dos setores comerciais ligados à indústria de adubos para aumento da produção e qualidade de bulbos. Em decorrência disso, têm surgido desequilíbrios nutricionais em várias propriedades, que resultam no aparecimento de sintomas visuais de deficiência nas plantas, principalmente relacionados com Manganês (Mn), Boro (B) e Zinco (Zn) (EPAGRI, 2000).

Dentre os micronutrientes, o B é o mais estudado na cebola, pois sua deficiência influencia na qualidade e o armazenamento dos bulbos, já que pode contribuir com perdas de peso, maior apodrecimento e maior alteração no sabor dos bulbos de cebola (RIBEIRO, 1978). Jayamohanrao (1974) verificou que a adição conjunta de $\mathrm{Cu}$ e de $\mathrm{B}$ melhorou a composição mineral dos bulbos, sobretudo no que se refere aos teores de $\mathrm{Ca}$, de $\mathrm{P}$ e de Fe. Ribeiro (1978) demonstrou a influência do B na qualidade e no armazenamento dos bulbos e verificou que os oriundos de plantas deficientes foram os que perderam mais peso, os que mais apodreceram e que tiveram maior alteração no sabor. Os bulbos deficientes em B apresentam as escamas mais externas endurecidas e enrugadas, e as mais internas, necrosadas (CALBO et al., 1986). Por sua vez, Peña et al. (1999) aplicaram 5,25 kg ha-1 de B e não obtiveram incremento na produtividade de peso dos bulbos fresco e secos.

Portanto esse sistema de adubação tem contribuído para elevar os custos de produção e os desequilíbrios nutricionais no campo que irão acarretar menor produção e qualidade. Além disso, não existem trabalhos de pesquisa na região de Monte Alto (SP) avaliando o efeito dessas técnicas de adubação de macro e micronutrientes na produtividade, na qualidade e na conservação dos bulbos de cebola. Assim justificam os estudos com aplicações de fertilizantes foliares na cultura, para avaliar a produtividade e a qualidade dos bulbos de cebola.

O presente trabalho objetivou avaliar o efeito da adubação foliar com micronutrientes, na produção e na classificação de diâmetro de bulbos da cebola na região de Monte Alto - SP.

\section{MATERIAL E MÉTODO}

Um ensaio de campo foi instalado na cidade de Monte Alto (SP), no período de maio a setembro de 2014, em solo classificado como Latossolo vermelho (EMBRAPA, 1999). Na área experimental, o cultivo de cebola vem sendo realizado há vários anos, no sistema de sucessão de culturas. Por ocasião do experimento foi realizada uma análise do solo, que apresentou as seguintes características: $\mathrm{pH}\left(\mathrm{H}_{2} \mathrm{O}\right)$ 5,9; M.O. $38 \mathrm{~g} \mathrm{~kg}^{-1}$; P-Mehlich-1 $12 \mathrm{mg} \mathrm{kg}{ }^{-1}$; K Mehlich 0,61 $\left.\mathrm{cmol}_{\mathrm{c}} \mathrm{kg}^{-1}\right)$; Ca trocável $\left(6,7 \mathrm{cmol}_{\mathrm{c}} \mathrm{kg}^{-1}\right) ; \mathrm{Mg}$ trocável (3,5 $\left.\mathrm{cmol}_{\mathrm{c}} \mathrm{kg}^{-1}\right) ; \mathrm{Zn}\left(1,8 \mathrm{mg} \mathrm{kg}^{-1}\right)$; $\mathrm{Mn}\left(30,2 \mathrm{mg} \mathrm{kg}^{-1}\right) ; \mathrm{B}\left(0,5 \mathrm{mg} \mathrm{kg}^{-1}\right)$ e CTC pH $714 \mathrm{mmol}_{\mathrm{c}} \mathrm{dm}^{-}$ 3 . 
A área foi preparada com auxílio de uma enxada rotativa, onde a adubação química de plantio foi realizada com base na análise do solo e nas doses utilizadas pelos produtores de cebola da região corrigida e adubada de acordo com as necessidades do cultivo da cebola $180 \mathrm{~kg} \mathrm{ha}^{-1} \mathrm{de} \mathrm{N}, 280 \mathrm{~kg} \mathrm{ha}^{-1}$ de $\mathrm{K}_{2} \mathrm{O}$ e 150 $\mathrm{kg} \mathrm{ha}^{-1}$ de $\mathrm{P}_{2} \mathrm{O}_{5}$. O híbrido de cebola utilizado no experimento foi o Cristalina, plantado no dia 12 de maio de 2014, com semeadora de 4 linhas duplas na densidade de 750 plantas/ha, no espaçamento de $0,50 \mathrm{~m}$ entre linhas e de 0,37 m de distância entre plantas na linha de plantio. A cultura foi mantida no limpo e irrigada, os demais tratos fitossanitários foram realizados de acordo com as recomendações para a cultura da cebola.

O delineamento experimental foi de blocos casualizados, com cinco repetições, onde as parcelas eram de $3 \mathrm{~m}$ x 2,6 m (área de 7,8 $\mathrm{m}^{2}$ ), constando de 6 linhas, onde foram feitas as avaliações nas 4 linhas centrais das parcelas. Foi considerado um espaçamento de $2 \mathrm{~m}$ entre as parcelas, livres de qualquer cultura ou planta invasora e $5 \mathrm{~m}$ entre os blocos. Para o experimento foram testados quatro tratamentos, conforme a tabela 1.

Para cada tratamento foram realizadas cinco aplicações em intervalos de 14 dias cada, iniciando a aplicação aos 34 dias após a semeadura (DAS). Na aplicação utilizou-se um pulverizador costal pressurizado, com barra munida com quatro pontas de jato leque (TT110/02), espaçadas de 0,50 m, trabalhando com pressão constante de $2,1 \mathrm{kgf} \mathrm{cm}^{-2}$, proporcionando o correspondente a $250 \mathrm{~L} \mathrm{ha}^{-1}$ de calda. No momento da aplicação registrou-se temperatura de $32^{\circ} \mathrm{C}$, umidade relativa de $59 \%$, vento em rajadas de $0,8 \mathrm{~km} \mathrm{~h}^{-1}$ e ausência de nebulosidade.

Tabela 1. Tratamentos realizados no ensaio de campo. Monte Alto, 2016.

\begin{tabular}{|c|c|c|c|}
\hline \multirow[b]{2}{*}{ Tratamentos } & \multicolumn{3}{|c|}{ Descrição } \\
\hline & $\begin{array}{c}\text { Produto } \\
\text { Comercial } \\
\end{array}$ & Dose & $\begin{array}{c}\text { Composição } \\
\left(\mathrm{g} \mathrm{L}^{-\mathbf{1}}\right)\end{array}$ \\
\hline Tratamento 1 & Controle & 0 & 0 \\
\hline Tratamento 2 & Liqui-Plex® Unix & $1,0 \mathrm{~L} \mathrm{ha}^{-1}$ & $\begin{array}{l}\mathrm{B}(6,70), \mathrm{Cu}(1,34), \mathrm{K}_{2} \mathrm{O}(26,80), \mathrm{Mg} \\
(26,80), \mathrm{Mn}(2,68), \mathrm{Mo}(2,68), \mathrm{N}(26,80), \\
\mathrm{P}_{2} \mathrm{O}_{5}(134), \mathrm{S}(14,34), \mathrm{Zn}(26,80)\end{array}$ \\
\hline Tratamento 3 & Bionex & $1,0 \mathrm{~L} \mathrm{ha}^{-1}$ & $\mathrm{~N}(96), \mathrm{P}_{2} \mathrm{O}_{5}(72), \mathrm{K}_{2} \mathrm{O}(84), \mathrm{Mo}(336)$ \\
\hline Tratamento 4 & Torped & $1,0 \mathrm{~L} \mathrm{ha}^{-1}$ & $\begin{array}{l}\mathrm{B}(7,1), \mathrm{Cu}(2,8), \mathrm{K}_{2} \mathrm{O}(113,6), \mathrm{Mg}(7,1), \\
\mathrm{Mn}(7,1), \mathrm{Mo}(1,4), \mathrm{N}(71,0), \mathrm{P}_{2} \mathrm{O}_{5}(113,6), \\
\mathrm{S}(35,5), \mathrm{Zn}(14,2), \mathrm{Ca}(14,2), \mathrm{Fe}(1,4)\end{array}$ \\
\hline
\end{tabular}

A colheita dos bulbos foi realizada em três de setembro, quando aproximadamente $75 \%$ das plantas apresentavam tombamento da parte aérea (estalamento), totalizando aproximadamente 115 dias de cultivo. Após serem arrancados, os bulbos foram dispostos sobre a superfície do solo, onde permaneceram por 17 dias até a conclusão da pré-cura. Após esse período, eles foram contados, pesados e acondicionados em sacos de ráfia telados, próprios para a comercialização de cebola.

Após a cura, os bulbos foram armazenados em galpão até fim de setembro, totalizando aproximadamente 140 dias. Nessa ocasião, as ramas foram cortadas, e os bulbos foram pesados e classificados.

Para analisar os dados, a produção foi primeiramente separada de acordo com a classificação da Ceagesp (2001) para cebolas, de acordo com o diâmetro transversal, onde classe 0 tem calibre menor de $15 \mathrm{~mm}$; classe 1 com calibre entre $15 \mathrm{~mm}$ e $35 \mathrm{~mm}$, classe 2 com calibre entre $35 \mathrm{~mm}$ e $50 \mathrm{~mm}$; classe 3 
com calibre entre $50 \mathrm{~mm}$ e $60 \mathrm{~mm}$; classe 3 extra com calibre entre $60 \mathrm{~mm}$ e $70 \mathrm{~mm}$; classe 4 com calibre entre $70 \mathrm{~mm}$ e $90 \mathrm{~mm}$; e classe 5 com calibre maior que $90 \mathrm{~mm}$.

As variáveis avaliadas foram número e peso dos bulbos, para isso foram contados e pesados; e a classificação do tamanho de bulbos de cebola, de acordo com a classificação da Ceagesp (2001), em classe 2, 3 e 4, realizadas na colheita da cebola.

Os dados foram submetidos à análise de variância pelo teste $\mathrm{F}$, onde as médias foram comparadas por meio do teste de Tukey a $5 \%$, utilizando-se o programa estatístico computacional SISVAR (Ferreira, 2011).

\section{RESULTADO E DISCUSSÃO}

Analisando a produção dos tratamentos do experimento, observa-se na Figura 1, que a controle obteve 128 bulbos; o tratamento com Lique-Plex, 127,2 bulbos; Bionex 129,4 bulbos; enquanto que o Torped, 129,2 bulbos; estatisticamente a produção dos tratamentos não apresentou diferença (Tabela 2). Ainda analisando a figura verificamos que para cada tratamento tivemos proporções diferente na qualidade dos bulbos (classe 2, classe 3 e classe 4 ) nesses tratamentos.

Figura 1. Classificação de tamanho de bulbos de cebola. Monte Alto, 2016.

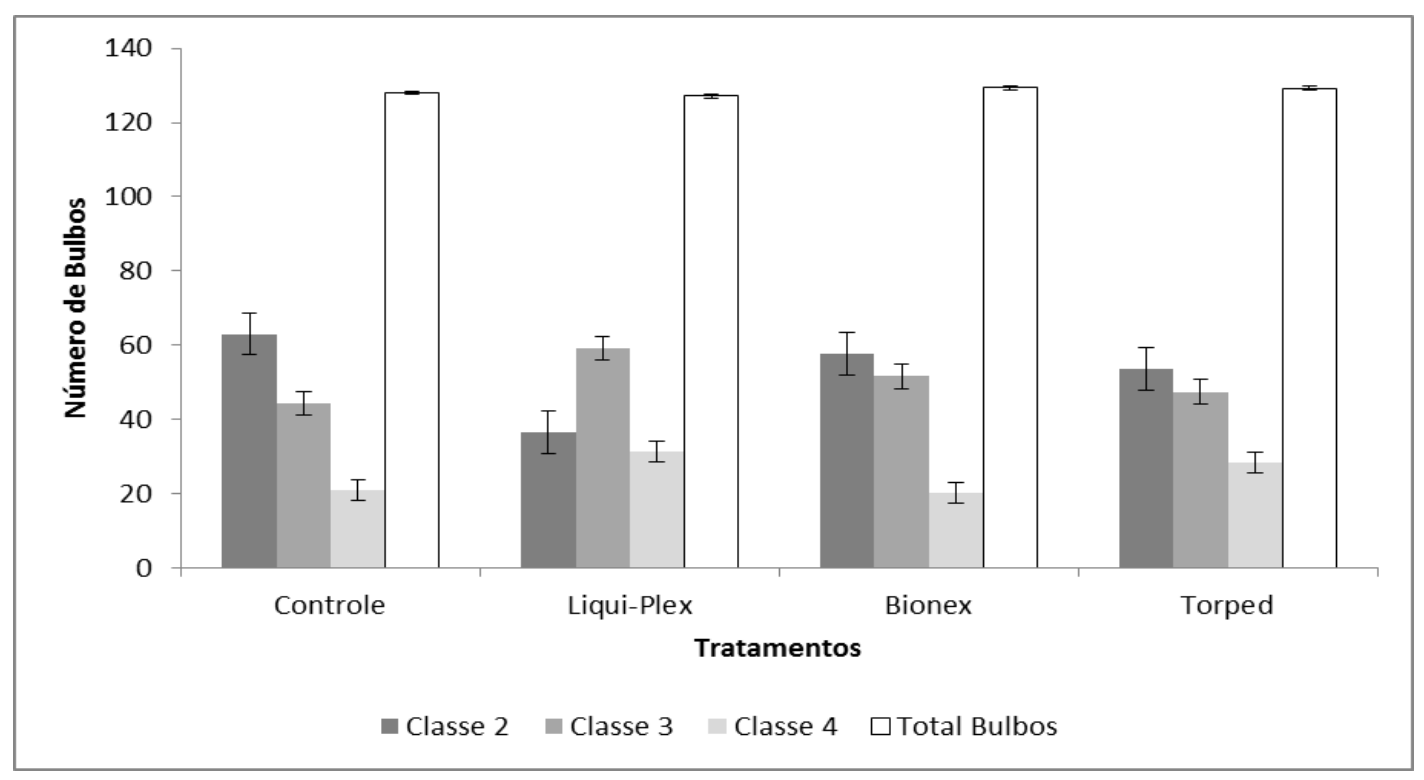

Assim a utilização do Lique-Plex no cultivo de cebola em sistema de plantio direto, com 4 linhas duplas, resultou em uma melhoria na percentagem do tamanho de bulbos, aumentando ao nível de 6,6 \% para a classe 3, e de 22,9 \% para tamanhos iguais ou superiores à classe 4 e uma redução em 43,2\% da quantidade de bulbos com tamanho igual ou menor que a classe 2 (Figura 1). 
Tabela 2. Produção de bulbos de cebola. Monte Alto, 2016.

\begin{tabular}{|c|c|c|c|c|}
\hline \multirow{3}{*}{$\begin{array}{l}\text { Tratamentos } \\
\text { Controle }\end{array}$} & \multicolumn{4}{|c|}{ Produção } \\
\hline & \multicolumn{2}{|c|}{$\mathrm{N}^{\mathrm{o}}$ Total de Bulbos } & \multicolumn{2}{|c|}{$\begin{array}{l}\text { Peso Total de Bulbos } \\
\quad\left(\mathrm{kg} \mathrm{parcela}^{-1}\right)\end{array}$} \\
\hline & 128,0 & $a^{1}$ & 23,20 & $\mathrm{c}^{1}$ \\
\hline Lique-Plex & 127,2 & $\mathrm{a}$ & 27,47 & $\mathrm{a}$ \\
\hline Bionex & 129,4 & $\mathrm{a}$ & 24,19 & $\mathrm{bc}$ \\
\hline Torped & 129,2 & $\mathrm{a}$ & 24,88 & $\mathrm{~b}$ \\
\hline F Blocos & $1,7018^{\mathrm{ns}}$ & & $2,1278^{\mathrm{n}}$ & \\
\hline $\mathrm{F}$ tratamentos & $3,778^{*}$ & & $22,61 * *$ & \\
\hline $\mathrm{CV}(\%)$ & 0,93 & & 3,44 & \\
\hline $\mathrm{dms}$ & 2,24 & & 1,61 & \\
\hline
\end{tabular}

A qualidade refletiu na avaliação do peso dos bulbos de cebola nos tratamentos (Tabela 2), observamos que o Lique-Plex, teve peso médio de $27,47 \mathrm{~kg}$, diferindo estaticamente dos outros tratamentos, Torped com 24,88 kg, Bionex com 24,19 kg e o de menor peso o controle com $23,20 \mathrm{~kg}$.

Avaliando a classificação dos bulbos (Tabela 3), verifica-se que, para a classe 2 o controle obteve o maior quantidade de bulbos (63 bulbos), em relação aos demais tratamentos (Lique-Plex 36,60; Bionex 57,60 e Torped 53,60 bulbos).

A classe 3, apresentou diferença estatística entre os tratamentos. O controle apresentou o menor valor (44,20 bulbos), em relação aos demais (Lique-Plex 59,20; Bionex 51,60 e Torped 47,40 bulbos); para a classe 4, o tratamento controle obteve o menor valor (20,80 bulbos) diferenciando dos tratamentos Lique-Plex e Torped (31,40 e 28,20 bulbos respectivamente) entretanto estatisticamente não diferiu do Bionex (20,20 bulbos). 
Tabela 3. Avaliação dos tratamentos nas classes dos bulbos de cebola. Monte Alto, 2016.

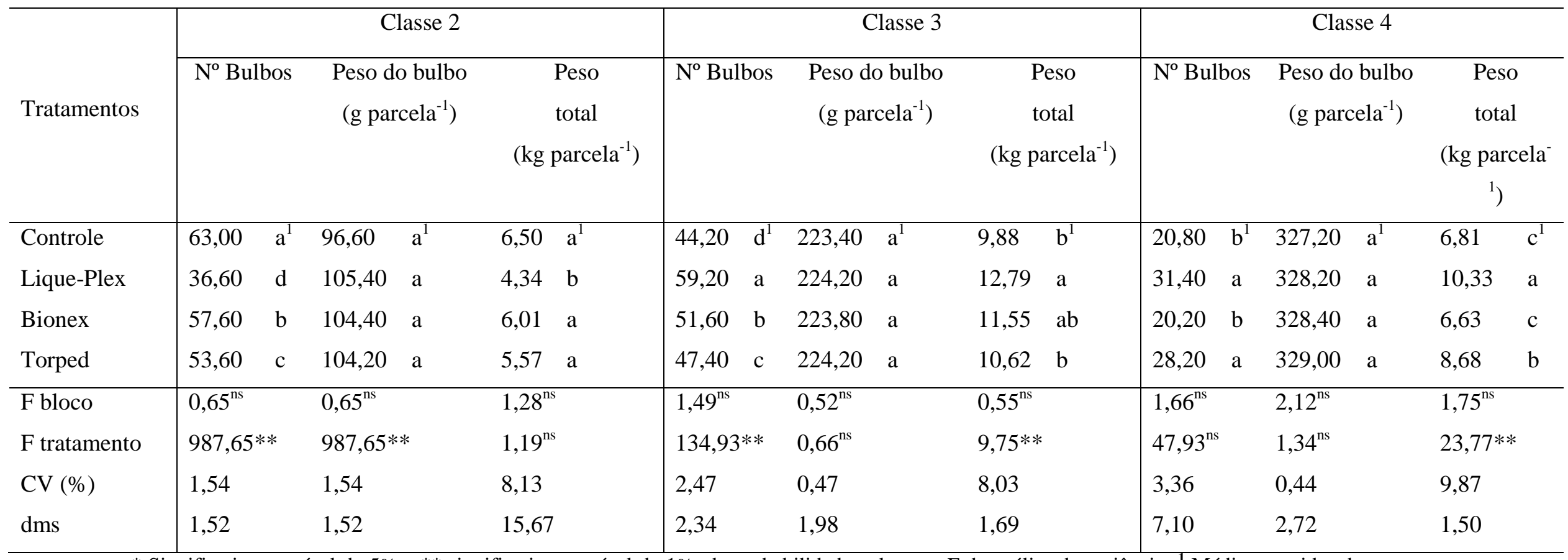

* Significativo ao nível de $5 \%$ e ** significativo ao nível de $1 \%$, de probabilidade pelo teste $\mathrm{F}$ da análise de variância. ${ }^{1}$ Médias seguidas da mesma letra na coluna não diferem significativamente entre si pelo teste de Tukey $(\mathrm{p}<0,05)$. 
$\mathrm{Na}$ variável peso médio de cada bulbo na classe 2 , o controle $(96,60 \mathrm{~g} / \mathrm{bulbo})$ não diferiu estatisticamente dos outros tratamentos (Lique-Plex 105,4 g; Bionex 104,40 g; Torped 104,20 g por bulbo); porém nas classes 3 e 4 os tratamentos não diferiram estatisticamente, para classe 2 o controle apresentou 223,40 g; Lique-Plex 224,20 g; Bionex com 223,80 g e Torped com 224,20 g por bulbo de cebola, e para a classe 4, o controle apresentou o resultado de 327,20 g; o Lique-Plex de 328,20; Bionex de 328,40 e Torped com 329,00 g por bulbo.

O peso total dos bulbos mostrou que o controle $(6,50 \mathrm{~kg})$ na classe 2 difere somente do Lique-Plex $(4,34 \mathrm{~kg})$, apresentou o menor valor, diferindo estatisticamente dos outros tratamentos. Na classe 3 não tivemos diferença entre eles, o controle obteve o menor resultado $(9,88 \mathrm{~kg})$, porém o Lique-Plex com $12,79 \mathrm{~kg}$ foi superior aos demais (Bionex 11,55 kg e o Torped 10,62 kg). Na classe 4, o controle e o Bionex, não se diferenciaram entre si (6,81 e 6,63 kg respectivamente), difere do Lique-Plex e Torped (10,33 e 8,68 kg).

Analisando o Lique-Plex, se destacou diante dos demais, pois na classe 2 obteve menor número de bulbos de cebola (cebolas de menor tamanho), enquanto que nas classe 3 e 4 se destacou com os maiores resultados, apresentando maior qualidade na produção de cebola.

Analisando o Bionex e Torped, eles apresentaram melhores resultados em relação a testemunha, porém inferiores ao Lique-Plex. Os resultados refletem tanto na classe 2, como na classe 3 e classe 4 .

Segundo Vidigal et al. (2010) a produção de bulbos de cebola com a aplicação de $43 \mathrm{t} \mathrm{ha}^{-1}$ de composto orgânico é suficiente para a obtenção de bulbos com ótima qualidade e produtividade.

Diferente dos resultados obtidos neste experimento, Kurts e Ernani (2010), estudando aplicação de micronutrientes na produção de cebola em cambissolos ( $\mathrm{pH}$ próximo de 6,0) não houve a necessidade de aplicar B ou Mn à cultura da cebola, tanto no solo como por meio de pulverizações foliares. Porém eles recomendam a aplicação de $\mathrm{Zn}$ ao solo ainda que o nível crítico esteja acima do indicado pelos órgãos regionais de pesquisa.

\section{CONCLUSÃO}

O tratamento com lique-Plex® proporcionou um aumento de produção e na classificação de diâmetro de bulbos de hibrido de cebola, "Cristalina", de classe 3 e 4.

\section{REFERÊNCIAS}

CALBO, M.E.R.; MONNERAT, P.H.; CHIMOYA, C. Caracterização de sintomas de deficiência de boro em cebola (Allium cepa L.) em estádio de produção. R. Ceres, v.33, p.274-280, 1986.

CEAGESP - COMPANHIA DE ENTREPOSTOS E ARMAZÉNS GERAIS DO ESTADO DE SÃO PAULO. Programa Brasileiro para a melhoria dos padrões comerciais e embalagens de hortigranjeiros. São Paulo: CEAGESP, 2001.

EPAGRI- Empresa de Pesquisa Agropecuária e Extensão Rural. 2000. Sistemas de produção para cebola: Santa Catarina. ( $3^{a}$ revisão). Florianópolis: Epagri, 91p. (Sistemas de Produção, 16).

EMBRAPA- Empresa Brasileira de Pesquisa Agropecuária. Sistema brasileiro de classificação de solos. Brasília: Serviço de Produção e Informação - SPI/EMBRAPA, 1999. 412p. 
FERREIRA, D.F. Sisvar: a computer statistical analysis system. Ciência e Agrotecnologia, v.35, p.10391042, 2011.

IBGE Instituto Brasileiro de Geografia e Estatística.. Indicadores IBGE: estatística da produção agrícola janeiro 2017. Rio de Janeiro: IBGE, 2017.

JAYMOHANRAO, V. Effect of copper and boron on the mineral composition of onion (Allium cepaL). Andhra Agric. J., v.17, p.170-172, 1974.

PEÑA, C.; AÑES, B.;DÁVILA, M. Respuesta de lacebolla(Allium cepa L.) a laaplicación de azufre, magnesio, cinc, y boro enunsuelo alcalino. Rev. For., v.43, p.173-182, 1999.

RIBEIRO, M.E.M. Caracterização de sintomas de deficiências de boro em pepino, alface, alho, beterraba, cebola e rabanete. 1978, 48 f. Dissertação (Mestrado em agronomia) - Universidade Federal de Viçosa.

SOUZA RJ; RESENDE GM. 2002. Cultura da cebola. Lavras: UFLA, 115p. (Textos Acadêmicos Olericultura, 21).

VIDIGAL, S. M. et al. Produção de cebola influenciada por doses, fontes e parcelamento de nitrogênio em diferentes épocas de cultivo no verão. Horticultura Brasileira, Brasília, v.18, p. 814-815, 2010. 